\title{
Dynamic Assessment of Global Maize Exposure to Extremely High Temperatures
}

\author{
Yuan Gao ${ }^{1,2} \cdot$ Peng $\mathrm{Su}^{3} \cdot$ Anyu Zhang ${ }^{1,2} \cdot$ Ran Wang ${ }^{1,2} \cdot$ Jing'ai Wang ${ }^{1,2,4}$
}

Accepted: 29 May 2021 / Published online: 16 June 2021

(C) The Author(s) 2021

\begin{abstract}
Exposure to extreme heat can severely harm crop growth and development, and it is essential to assess such exposure accurately to minimize risks to crop production. However, the actual distribution of crops and its changes have neither been examined in sufficient detail nor integrated into the assessments of exposure to ensure their accuracy. By examining the distribution of maize at a high resolution through species distribution modeling, we assessed the past and future exposure of maize to temperatures above $37^{\circ} \mathrm{C}$ worldwide. Such exposure is likely to be widespread and severe, mainly in the subtropics, and may even expand to the mid-latitudes to encompass some major maize-producing areas. Many areas at both high and low latitudes may become exposed for the first time in the next 20 years. By the 2050s, the total area exposed could increase by up to $185 \%$ to 308.18 million ha, of which the area exposed for over 60 days may increase nearly sevenfold. The average length of exposure may increase by $69 \%$ to 27 days, and areas optimally suited to maize planting may see the fastest increase by up to $772 \%$. Extreme heat can threaten global maize production
\end{abstract}

Jing'ai Wang

jwang@bnu.edu.cn

1 Faculty of Geographical Science, Beijing Normal University, Beijing 100875, China

2 Key Laboratory of Environmental Change and Natural Disaster of the Ministry of Education, Beijing Normal University, Beijing 100875, China

3 School of Geographic Science, Qinghai Normal University, Xining 810008, China

4 Academy of Plateau Science and Sustainability, Xining 810008, China severely, and measures to mitigate that threat and to adapt to it are urgently needed.

Keywords Climate change Exposure to extreme heat - Maize - Maxent model - Potential maize distribution

\section{Introduction}

Along with the worldwide rising mean temperature, the frequency and intensity of extreme high-temperature events have increased in the past few decades, and the trend is expected to continue in the near future (IPCC 2014). Exposure to extremely high temperatures can induce morphological, physiological, and biochemical changes in crops, seriously impacting crop growth and development and even leading to crop failure (Stone 2001; Wahid et al. 2007). Therefore, in the context of climate change, it is more imperative than ever to evaluate accurately a crop's exposure to extremely high temperatures to lower the risk to crop production and to ensure food security.

Under the framework of disaster risk assessment (Shi 2019), exposure involves two aspects - the hazard and the elements at risk. Both can vary over time, especially in the context of accelerating global change. Thus, exposure should be viewed as a dynamic process, and exposure is increasingly being assessed dynamically (Dhondt et al. 2012; Freire and Aubrecht 2012; Pittore et al. 2016).

Crop exposure in relation to extreme climate can be defined as the presence of crops in settings adversely affected by climatic stress (Anandhi et al. 2016). Crop exposure can thus vary not only with climate change but also with changes in crop distribution. 
However, changes in the potential distribution of crops that typically result from climate change, although widely predicted (Ureta et al. 2012; Zabel et al. 2014; Shabani and Kotey 2016; Ramirez-Cabral et al. 2017; Yue et al. 2019), have yet to receive adequate attention from those conducting research on such exposure. Some studies simply simulated the distribution and intensity of extreme weather events within a major growing region (Zhang et al. 2018a; Wang et al. 2020) to characterize crop exposure, but did not take into account the actual distribution of the particular crops on a spatial scale fine enough for precise quantification. Other studies used gridded global data on crop distribution to examine current and future exposure. Gourdji et al. (2013) used randomly selected grid cells in which harvested area accounted for at least $10 \%$ of the total area as representing crop locations, whereas Zhang et al. (2018b) defined grids with at least 10,000 ha under maize as maize-growing grids. Regardless of these differences, what was common to all these studies was the use of past distribution as a proxy for future distribution for estimating the exposure of crops to future climates.

Instead of treating crop distribution as a static input, Teixeira et al. (2013) identified hotspots of heat stress for crops, with their distribution simulated dynamically using the Global Agro-Ecological Zones (GAEZ) model; however, the study was performed using less mechanistic modeling procedures and at a coarse spatial resolution using only a single general circulation model (GCM) and only one climate scenario, resulting in relatively large uncertainties. Wang et al. (2019) analyzed the past and future patterns of rice exposure to high temperatures worldwide, with the potential distribution of the crop simulated by assessing the suitability of land based on multiple criteria. Despite such refinements, the predicted distributions are not accurate enough so far, given the methodological limitations, including subjectivity in the selection of environmental variables for suitability assessment.

Overall, a critical shortcoming of existing crop exposure studies is that they focus more on the changes of climatic stress, such as high temperature, but tend to give less attention to potential changes in crop distribution or to their precise quantification. In terms of evaluating risks from disasters, such studies focus on the hazard but ignore the elements at risk, thereby making the predictions and in turn the assessment less accurate. This is partly due to lack of data or of the algorithms required for modeling crop distribution more accurately. However, the recent availability of high-resolution environmental and socioeconomic data sets, in combination with more refined techniques of simulation, makes it possible to model the potential distribution of crops more accurately, thereby overcoming the above-mentioned limitations.
As one of the most important staple foods, maize (Zea mays L.) supports millions of people worldwide (Ranum et al. 2014). Although the growth and development of the crop are equally, and critically, sensitive to extreme heat (Hatfield et al. 2011; Lobell et al. 2013), maize's exposure to extremely high temperatures as a result of climate change remains to be accurately evaluated-a shortcoming the present study sought to overcome by combining, at higher spatial resolution, the dynamic projections not only of high temperatures but also of the worldwide distribution of maize.

\section{Materials and Methods}

This study was organized as follows by: (1) quantifying the intensity of the hazard of extremely high temperatures, (2) simulating the potential distribution of maize, and (3) assessing and analyzing the exposure of maize to extreme heat worldwide. The research framework is shown in Fig. 1.

\subsection{Calculating the Intensity of the Hazard of High Temperature}

Based on IPCC (1996), extreme high temperatures for maize were taken as those higher than $37^{\circ} \mathrm{C}^{\circ} \mathrm{C}$. The number of days during the growth period of maize on which the daily maximum temperature was above $37^{\circ} \mathrm{C}$ was taken as the indicator of the intensity of the hazard, namely extremely high temperatures, which was quantified by combining the daily maximum temperature data (Thrasher and Nemani 2012) with global data on the sowing and harvesting dates for maize (Sacks et al. 2010). The generated data were taken as the hazard data for exposure assessment.

\subsection{Predicting the Potential Distribution of Maize}

The distribution of crops is influenced by both physical and socioeconomic factors. However, on a large scale, it is the combination of biophysical factors including terrain, climate, and soil that allows a given crop to be cultivated in a specific area (Baker and Capel 2011). Therefore, we mainly considered the biophysical suitability for predicting the potential distribution of maize using the maximum entropy (Maxent) model. In addition, the land use factor was taken into consideration. The procedures are outlined in Fig. 2 and described in detail below.

Maxent is one of the species distribution models (SDMs) that investigate the relationships between known species distribution and environmental characteristics at the locations, and then based on such relationship make predictions on the potential distribution of the target 
Fig. 1 Research framework for the dynamic assessment of global maize exposure to extremely high temperatures

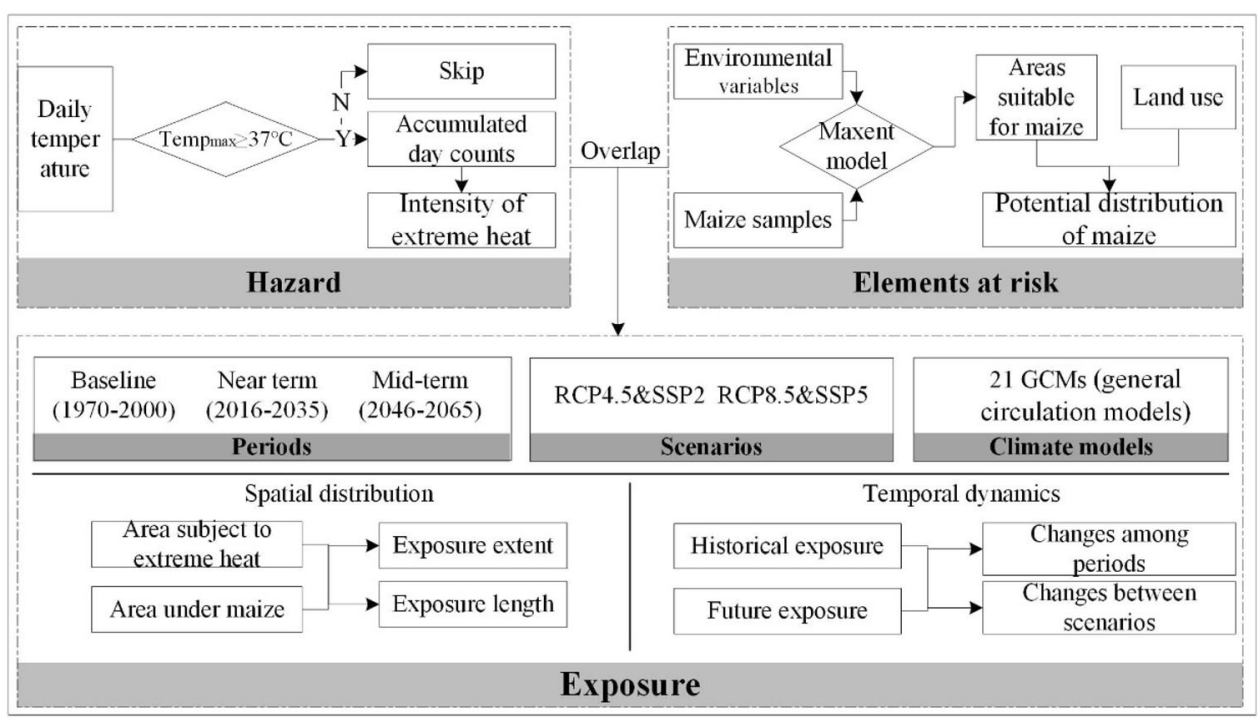

species (Yue et al. 2019). Among the many available SDMs, Maxent has exhibited better predictive capability and accuracy than others (Elith et al. 2006). Using presence-only species records and environmental predictors, the Maxent model is able to derive the probability distribution of a species' occurrence (Phillips et al. 2006; Elith et al. 2011) based on the maximum-entropy principle. The principle is to select a probability distribution with maximum entropy under certain constraints, considering it as the best explanation for an unknown distribution (Phillips et al. 2006; Fourcade et al. 2014). Maxent has been successfully applied to predicting the distribution of crops, among them maize (He et al. 2019; Kogo et al. 2019) and wheat (Sun et al. 2012; Yue et al. 2019). The simulation steps using Maxent are described below.

\subsubsection{Generating Data on the Occurrence of Maize}

Appropriate selection of representative samples from existing species occurrence data is significant to ensuring the performance of SDMs (Araújo and Guisan 2006). This becomes more so for species with a wide geographic range and uneven spatial distribution, such as maize. Here we referred to the sampling method by Yue et al. (2019) to sample the representative occurrence points of maize worldwide to ensure a suitable sample size and random distribution of the points and to lower biases in sampling. Using past $0.25^{\circ}$ by $0.25^{\circ}$ gridded data on the fraction of maize-harvested area (FMHA) derived from Monfreda et al. (2008), we divided the maize grids into four groups based on that fraction-FMHA up to 5\%; more than 5\% up to $10 \%$; more than $10 \%$ up to $33 \%$; and more than $33 \%$. For all the cells in the last group, we calculated the mean area under maize planting, which was then used as the reference value for determining the sample size for the
Fig. 2 Procedures for predicting the potential distribution of maize worldwide

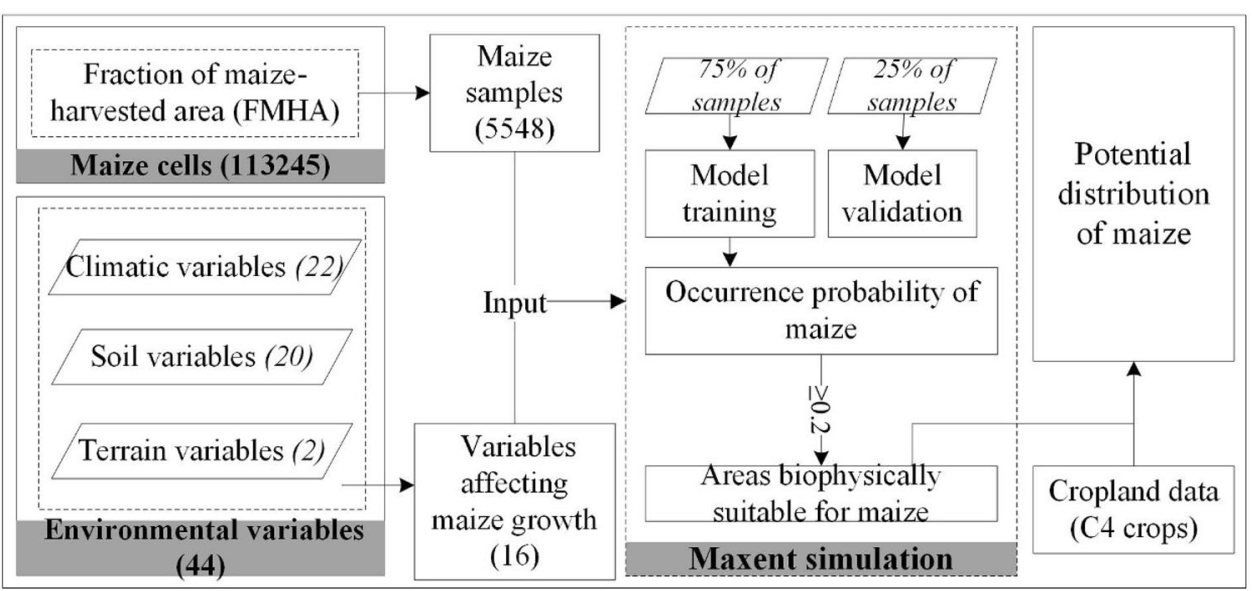


Table 1 Selection of maize samples for Maxent modeling

\begin{tabular}{llllll}
\hline Fraction of maize-harvested area $(\%)$ & $<5$ & $5-10$ & $10-33$ & $\geq 33$ & Total \\
\hline Number of grids & 102390 & 5373 & 4830 & 652 & 113245 \\
Area under maize (1,000 ha) & 41827.7 & 25051.7 & 53219.5 & 15998.1 \\
Sample size & 1705 & 1022 & 2169 & 652 & 136097 \\
\hline
\end{tabular}

other three groups. The final tally was 5,548 samples, or $4.9 \%$ of all the maize cells. Of the cells with FMHA of more than $5 \%$, which accounted for $69.3 \%$ of the global harvested area of maize, $35.4 \%$ were included in the sample (Table 1). Therefore, the range and the high values of FMHA were balanced in the sampling process. The Matlab randperm function was used for randomly selecting the specified number of samples. The process was repeated 30 times to balance the sampling efficiency and robustness, according to our prior uncertainty test (by the same method as Su et al. (2021) used for rice), thus generating 30 groups of samples.

\subsubsection{Screening Environmental Variables}

A key step in good species distribution modeling practice is the improved selection of environmental variables that serve as inputs for the models, specifically, ensuring the functional relevance and completeness of the variables and dealing with correlated ones (Elith and Leathwick 2009). We selected the environmental variables required for Maxent modeling through statistical analyses of past data on the FMHA (Monfreda et al. 2008) and 44 biophysical variables, comprising 22 climatic variables defined by Hijmans et al. (2005), 20 soil variables from Batjes (2016), and 2 terrain variables from Fischer et al. (2008) and Danielson and Gesch (2011). First, we constructed the probability distribution function (PDF) separately for each variable within the global terrestrial cells and within the maize cells. Second, we calculated the Kullback-Leibler $(K L)$ divergence (Kullback and Leibler 1951) between the two PDFs, and retained those variables with $K L$ values no less than 1 (Su et al. 2021) for further screening. The logic behind this choice was that a low divergence indicates only a small difference between the distributions, implying that the variable is not particularly important for maize growth. Finally, we calculated the Pearson correlation coefficient (r) matrix of the retained variables. Within each pair of variables with a high correlation coefficient $(|\mathrm{r}| \geq 0.8)$ (Evans et al. 2010), we kept the one with a higher $K L$ value to minimize multicollinearity and to avoid overfitting. In this way, 16 crucial environmental variables were selected-10 were climatic, 5 were related to soil, and 1 was terrain related (Table 2).

\subsubsection{Application of the Maxent Model}

The samples and the environmental variables obtained by following the above procedures were combined to run the Maxent model. We used $75 \%$ of the samples for training the model and the remaining $25 \%$ for validating it. Next, the threshold-independent area under the curve (AUC) of the receiver operator characteristic (ROC) was adopted to evaluate the performance of the Maxent model. The model was then used for calculating the probability that maize is present in a given cell. Each of the above-mentioned 30 sets of maize samples was used for a run and the resulting probabilities were averaged. Grid cells with a mean probability greater than 0.2 (Kogo et al. 2019) were identified as being biophysically suitable for maize cultivation.

These cells were then overlaid with data on the gridded cropland area devoted to the cultivation of $\mathrm{C} 4$ annual crops from the land-use harmonization 2 (LUH2) data sets from Hurtt et al. (2020) to incorporate the land-use factor. ${ }^{1}$ The purpose of this step was to confine the assessment of land in terms of its suitability for maize (based on biophysical factors) to actual cropland so as to make the predictions of the distribution of maize more accurate. In this way, we finally determined the potential distribution of maize, which was then used as the data on the elements at risk for assessing its probable exposure to the hazard of extremely high temperatures.

\subsection{Assessing Exposure of Maize to Extremely High Temperatures}

After calculating the intensity of the hazard (as described in Sect. 2.1) and predicting the global distribution of maize (Sect. 2.2), we evaluated the exposure of maize to extreme heat globally (referred to as "maize exposure"). The area under maize planting and suffering from extreme heat was determined as follows:

$$
\begin{aligned}
\text { Range }_{\text {exp }} & =\text { Range }_{\text {heat }} \cap \text { Range }_{\text {maize }} \\
& =\left\{C \mid C \in \text { Range }_{\text {heat }} \text { and } C \in \text { Range }_{\text {maize }}\right\}
\end{aligned}
$$

\footnotetext{
${ }^{1}$ Crops that fix $\mathrm{CO} 2$ first into a four-carbon (C4) carbohydrate to increase their photosynthetic efficiency, and maize is a major $\mathrm{C} 4$ crop (Long and Spence 2013).
} 
Table 2 Biophysical variables used for Maxent modeling

\begin{tabular}{lll}
\hline Category & Name & Definition \\
\hline BIO2 & Mean diurnal range (mean of monthly max temp-min temp) \\
BIO3 & Isothermality (BIO2/BIO7) $(* 100)$ \\
BIO5 & Max temperature of warmest month \\
BIO9 & Mean temperature of wettest quarter \\
BIO16 & Mean temperature of driest quarter \\
BIO18 & Precipitation of wettest quarter \\
Solar radiation & Precipitation of warmest quarter \\
Wind speed & \\
Water vapor pressure & \\
CFRAG & \\
CNrt & Coarse fragments $\%(>2$ mm) \\
GYPS & C/N ratio \\
ORGC & Gypsum content \\
TAWC & Organic carbon content \\
Elevation & Total available water capacity $\left(-33\right.$ to $\left.-1500 \mathrm{kPa}, \mathrm{cm} \mathrm{m}{ }^{-1}\right)$ \\
\hline
\end{tabular}

where Range $_{\text {exp }}$ is the exposure range, Range $e_{\text {heat }}$ is the area subject to extreme heat, Range $_{\text {maize }}$ is the distribution range of maize, and $C$ represents a terrestrial grid.

For any exposed cell, the number of days during the maize growth period on which the daily maximum temperature was above $37^{\circ} \mathrm{C}$ was used to quantify the length or duration of exposure, and the area under $\mathrm{C} 4$ crops within that cell was taken as the exposure area. It should be noted that we used the area under $\mathrm{C} 4$ crops as a proxy for the area under maize planting - the reasons for this assumption and its limitations are discussed in Sect. 4.3.

Spatially explicit assessments were performed for three periods - the past, or 1970-2000 (which served as the datum); the near term, or 2016-2035; and the mid-term, or 2046-2065-and under two combinations of representative concentration pathway (RCP)-based climate projections and the corresponding shared socioeconomic pathway (SSP)-based socioeconomic scenarios, that is RCP4.5SSP2 and RCP8.5-SSP5, which represent a low stabilization scenario that stabilizes radiative forcing at $4.5 \mathrm{~W} / \mathrm{m}^{2}$, and a very high emission scenario that puts the radiative forcing at $8.5 \mathrm{~W} / \mathrm{m}^{2}$ by 2100 (Hurtt et al. 2020). We further analyzed the distributions and changes of the exposure under different scenario-period combinations characterized through spatial-temporal patterns (Sect. 3.1) and statistical characteristics (Sect. 3.2).

\subsection{Sources of Data}

Table 3 lists and describes the data used in this study. The data were converted to match the spatial resolution, $0.25^{\circ}$, of the daily meteorological data provided by Thrasher and Nemani (2012). The bilinear interpolation method was used to reduce the spatial resolution of some original raster data sets, while the aggregation (mean) method was use to increase the resolution of others. The FMHA was calculated by dividing the total harvested area within each $0.25^{\circ}$ grid by the total land area of that grid.

Of the 22 climatic variables that were used, data for 19 bioclimatic variables were generated based on the data on daily temperature and precipitation from Thrasher and Nemani (2012) using the Biovars function in the R package dismo provided by Hijmans et al. (2005). Data on the other three variables-solar radiation, wind speed, and water vapor pressure-were generated based on the data on their daily values from Warszawski et al. (2014). The data on climatic variables were averaged over the decades within each study period, as was the intensity of the hazard.

For projections of the future situation, we used a multimodel ensemble approach to reduce uncertainty. For a given grid cell, we adopted the average number of growthperiod days with extreme heat under 21 GCMs used by Thrasher and Nemani (2012) to quantify the intensity of the high-temperature hazard. We used the mean value of the probability that maize would be grown in a given grid as generated by Maxent along with climate data from 
Table 3 List of data employed in the study on the dynamic assessment of global maize exposure to extremely high temperatures

\begin{tabular}{|c|c|c|c|}
\hline Category & Name (content) & Source and reference & Resolution \\
\hline $\begin{array}{l}\text { Maize } \\
\text { distribution }\end{array}$ & Maize harvested area & $\begin{array}{l}\text { Center for Sustainability and the Global } \\
\text { Environment (SAGE), University of Wisconsin- } \\
\text { Madison (Monfreda et al. 2008) }\end{array}$ & $5^{\prime} \times 5^{\prime}, 2000 s$ \\
\hline $\begin{array}{l}\text { Maize growth } \\
\text { period }\end{array}$ & Mean maize planting and harvesting dates & $\begin{array}{l}\text { Center for Sustainability and the Global } \\
\text { Environment (SAGE), University of Wisconsin- } \\
\text { Madison (Sacks et al. 2010) }\end{array}$ & $5^{\prime} \times 5^{\prime}, 2000 s$ \\
\hline \multirow[t]{2}{*}{ Climate } & $\begin{array}{l}\text { NASA Earth Exchange Global Daily Downscaled } \\
\text { Projections (NEX-GDDP) (daily maximum } \\
\text { temperature, minimum temperature, and precipitation) }\end{array}$ & $\begin{array}{l}\text { NASA Center for Climate Simulation (NCCS) } \\
\text { (Thrasher and Nemani 2012) }\end{array}$ & $\begin{array}{r}0.25^{\circ} \times 0.25 \\
1950-2100\end{array}$ \\
\hline & $\begin{array}{l}\text { Daily solar radiation, wind speed, and water vapor } \\
\text { pressure }\end{array}$ & $\begin{array}{l}\text { The Inter-Sectoral Impact Model Intercomparison } \\
\text { Project (ISI-MIP) (Warszawski et al. 2014) }\end{array}$ & $\begin{array}{l}0.5^{\circ} \times 0.5^{\circ} \\
1971-2099\end{array}$ \\
\hline Soil & ISRIC-WISE derived soil properties (WISE30sec) & $\begin{array}{l}\text { International Soil Reference and Information } \\
\text { Centre (ISRIC) (Batjes 2016) }\end{array}$ & $\begin{array}{l}30^{\prime \prime} \times 30^{\prime \prime} \\
2016\end{array}$ \\
\hline \multirow[t]{2}{*}{ Terrain } & $\begin{array}{l}\text { Global multi-resolution terrain elevation data } 2010 \\
\text { (GMTED2010) }\end{array}$ & $\begin{array}{l}\text { United States Geological Survey (USGS) } \\
\text { (Danielson and Gesch 2011) }\end{array}$ & $\begin{array}{l}30^{\prime \prime} \times 30^{\prime \prime} \\
2010\end{array}$ \\
\hline & Global Terrain Slope & $\begin{array}{l}\text { Food and Agriculture Organization (FAO) (Fischer } \\
\text { et al. 2008) }\end{array}$ & $5^{\prime} \times 5^{\prime}, 2000$ \\
\hline Land use & Gridded cropland area of $\mathrm{C} 4$ annual crops & $\begin{array}{l}\text { Land-Use Harmonization } 2 \text { (LUH2), Global } \\
\text { Ecology Laboratory, University of Maryland } \\
\text { (Hurtt et al. 2020) }\end{array}$ & $\begin{array}{r}0.25^{\circ} \times 0.25^{\circ} \\
1970-2100\end{array}$ \\
\hline
\end{tabular}

different GCMs as inputs to predict the biophysical suitability of maize.

Because future data on the soil, terrain, and growth periods were not available and because the potential changes could be relatively small, we used past data on these variables for future assessments as well.

\section{Results}

This section presents the most important outcomes of our research on the exposure of global maize to growth-period extreme heat, regarding its spatiotemporal patterns and statistical characteristics.

\subsection{Spatiotemporal Patterns of Maize Exposure to High Temperatures}

In this section, we first analyze the spatial patterns of maize exposure under different RCP-SSP scenarios and during different periods, and then examine its variations between periods and scenarios.

\subsubsection{Spatial Distribution}

Historically, maize-growing areas in West Asia, South Asia, the Sahel, and along the United States-Mexico border faced prolonged exposure to extremely high temperatures (Fig. 3a). Over large areas of eastern Iraq such temperatures were recorded on more than 90 days during the growth period; in many areas in Syria, Iran, Afghanistan, northeastern Pakistan, central Sudan, and northeastern Mexico, on 60-90 days; and in some areas of the southern United States and of central Asia, on 30-60 days. In contrast, in most of the areas suitable for maize planting in southern Europe, southern Africa, India, China, Southeast Asia, Australia, the United States, Brazil, and Argentina, such conditions were encountered on fewer than 30 days.

Similar patterns tended to continue under the combination RCP4.5-SSP2 during the near term (Fig. 3b). Some areas in Iran, Afghanistan, and Pakistan recorded more than 90 days of extremely high temperatures; many areas of the southeastern parts of central Asia, 60-90 days; and the Sahel, the southern United States, and the Gran Chaco in South America, 30-60 days. Under the same combination during the mid-term (Fig. 3c), many areas in Iran, Afghanistan, and Pakistan recorded such exposure on more than 90 days; in the southern United States and the Gran Chaco, on 60-90 days; in southern Africa, on 30-60 days; and in the North China Plain and Southeast Asia, on 10-30 days.

Under the combination RCP8.5-SSP5 in the near term (Fig. 3d), the pattern was generally similar to that under the RCP4.5-SSP2 in the near term. However, by the mid-term (Fig. 3e), many areas in northern Syria, Afghanistan, 
Fig. 3 Exposure of maize to extremely high temperatures worldwide under different combinations of RCPs and SSPs over different periods. a In the past: 1970-2000, b in the near term (2016-2035) under RCP4.5-SSP2, $\mathbf{c}$ in the mid-term (2046-2065) under RCP4.5-

SSP2, $\mathbf{d}$ in the near term under RCP8.5-SSP5, and e in the midterm under RCP8.5-SSP5. RCP representative concentration pathway, SSP shared socioeconomic pathway
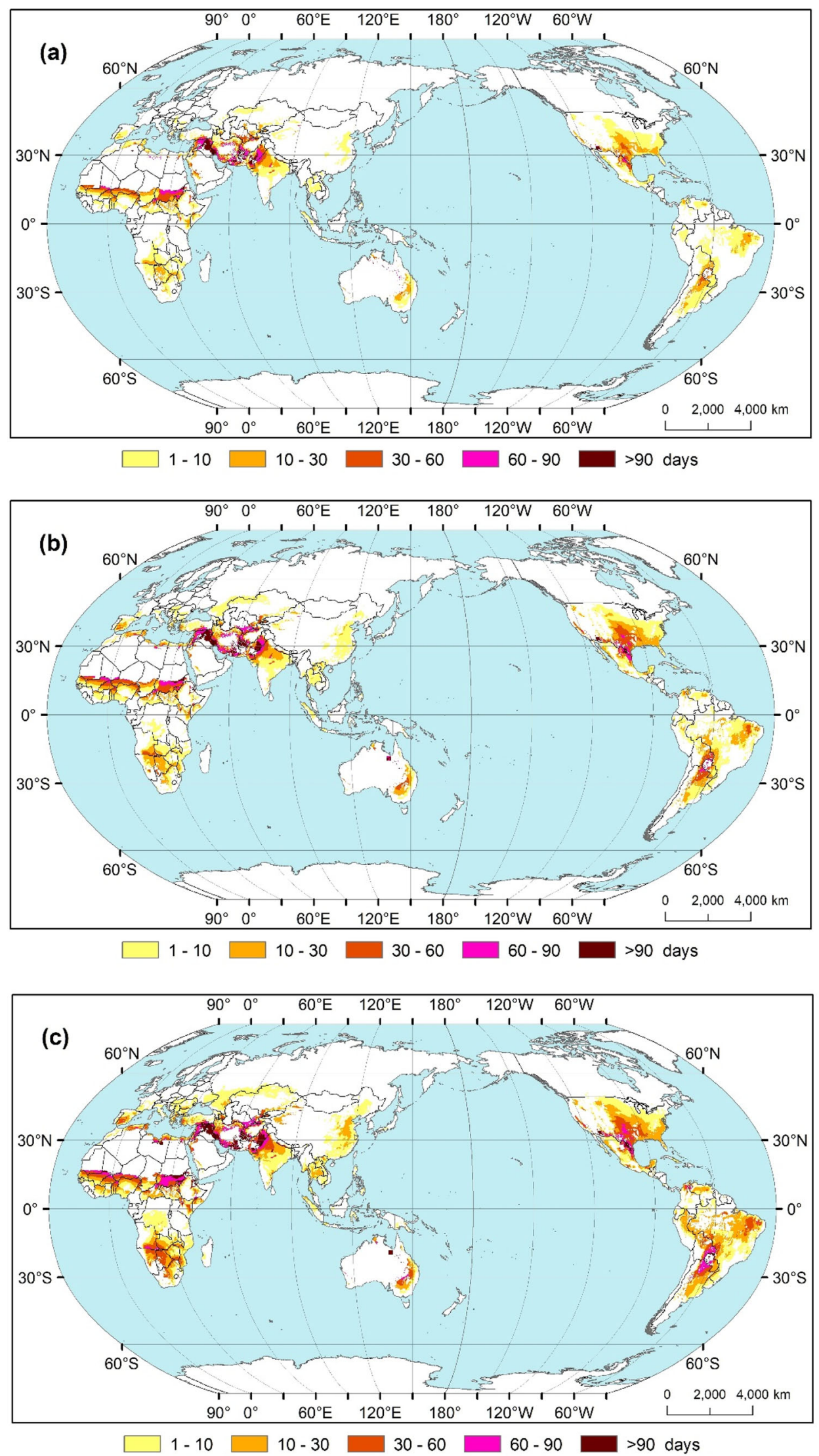
Fig. 3 continued
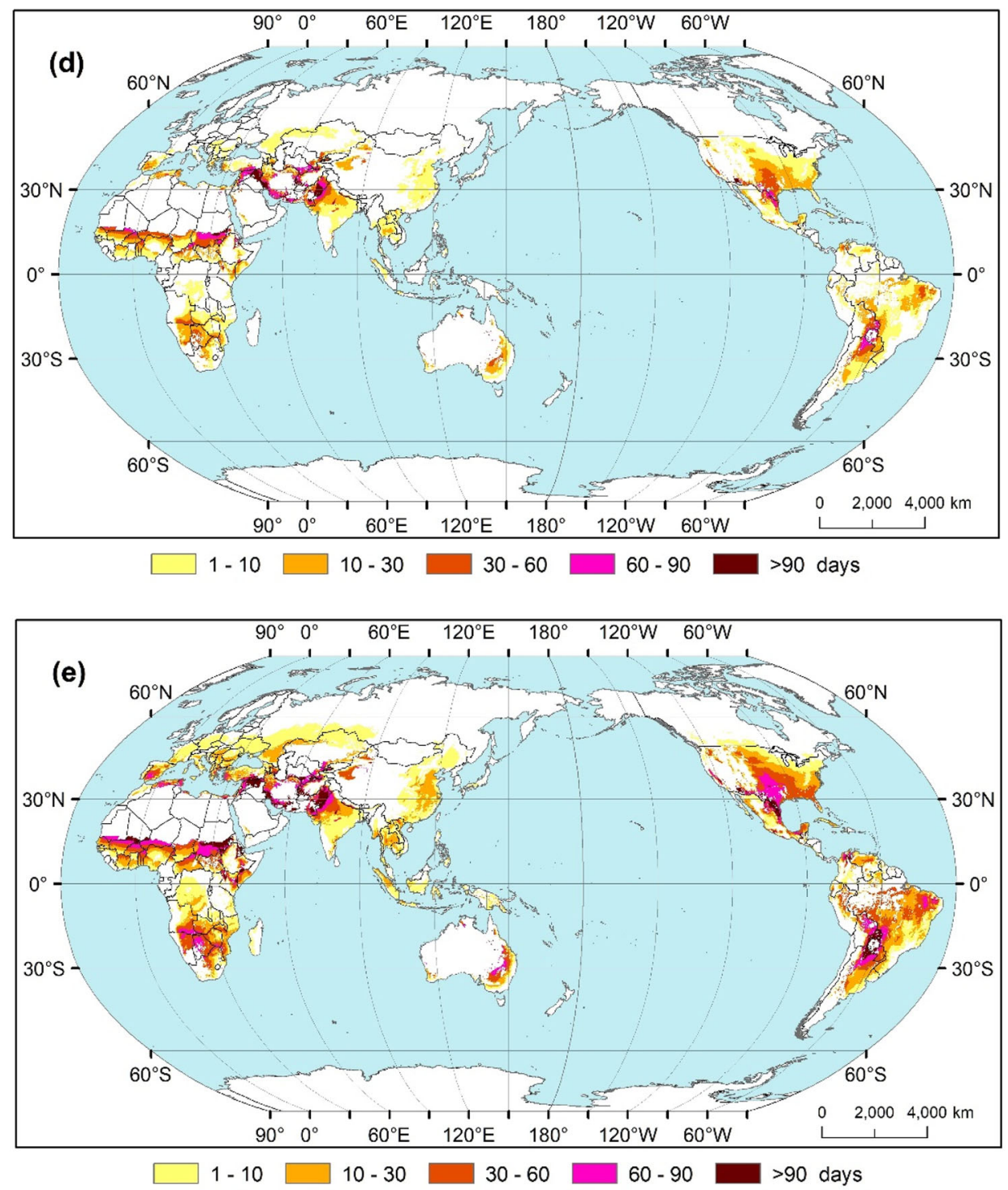

northeastern Pakistan, the United States-Mexico border, and the northern Gran Chaco are likely to record such extremely high temperatures during the growth period of maize on more than 90 days; areas in most of the Sahel, southern Africa, southern Europe, and southeastern Australia, on more than 30 days; and most of eastern China, northern India, Southeast Asia, the United States, Brazil, and Argentina, on more than 10 days. But eastern Iraq and southeastern Iran will practically cease to experience such days.

\subsubsection{Temporal Changes}

The variations of exposure between different periods and under different scenarios were further analyzed by making pairwise comparisons, that is by comparing the exposures under a given RCP-SSP scenario over future periods with those in the past, and by comparing the exposures for a given period under one scenario with those under a different scenario.

Under the RCP4.5-SSP2 scenario, in the near term (Fig. 4a), the number of days of exposure is generally higher than that in the past by 1-10 days across most of the maize-growing areas globally. The increase of exposure length can be greater, by 10-30 days in some regions, including most of Pakistan, Afghanistan, Iran, Syria, the southeastern parts of central Asia, the south-central United States, the Gran Chaco, the coastal Mediterranean regions, the Sahel, southern Africa, and southeastern Australia. Such patterns will continue in the mid-term (Fig. 4b) with an increase of 10-30 days in most of the Sahel, southern Africa, southeastern Australia, the central United States, Peru, Brazil, northwestern India, and some parts of the North China Plain. The exposure length can rise by over 30 
Fig. 4 Exposure of maize to extremely high temperatures worldwide relative to that in the past (1970-2000, the datum) under different combinations of RCPs and SSPs over different periods. a Near term

(2016-2035) under RCP4.5-

SSP2, b Mid-term (2046-2065) under RCP4.5-SSP2, c Near term under RCP8.5-SSP5, and d Mid-term under RCP8.5SSP5. NE, never-exposed zones; E2N, exposed zone ceasing to be exposed, N2E, zones never exposed before but now exposed. $R C P$ representative concentration pathway, SSP shared socioeconomic pathway

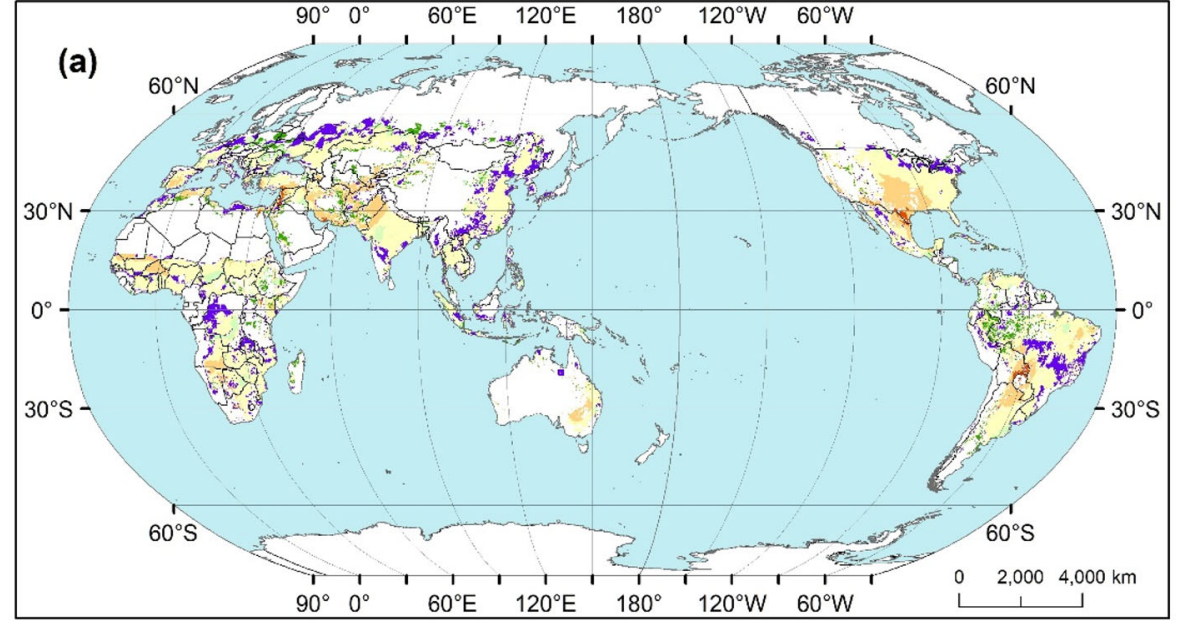

$\checkmark$ NE $\square 2 N \square$ N2E $\square<=0 \quad \square 0-10 \square$ 10-30 $\square$ 30-60

$>60$ days
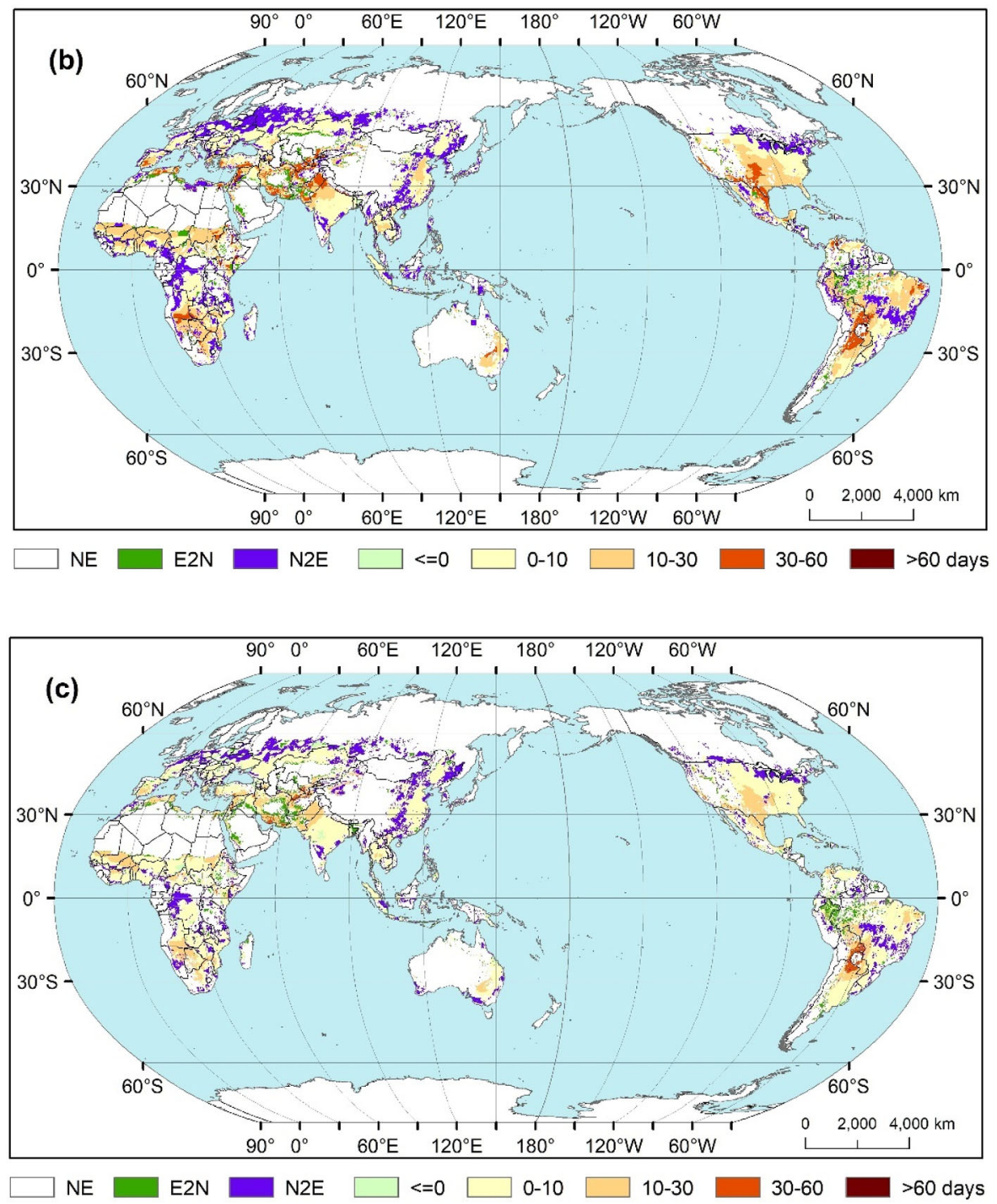
Fig. 4 continued

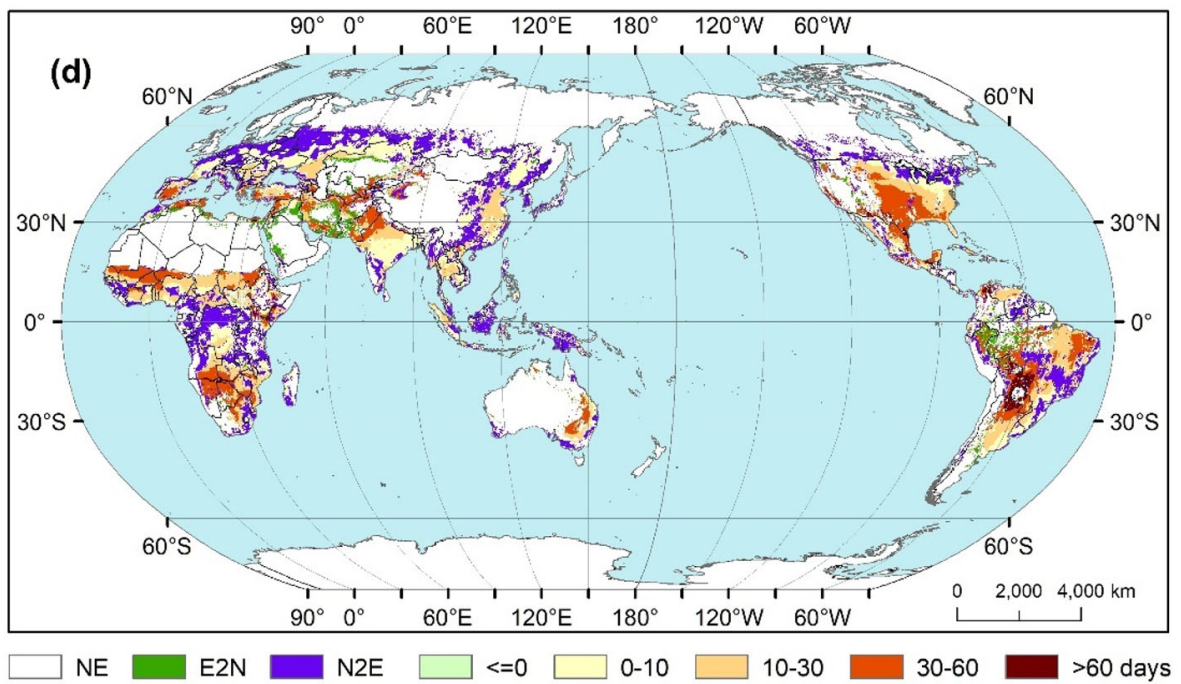

days in many areas of the Mediterranean region, Iran, Afghanistan, Pakistan, the southeastern parts of central Asia, along the United States-Mexico border, and the Gran Chaco.

Under the RCP8.5-SSP5 scenario during the near term (Fig. 4c), the changes in exposure relative to the past are slightly higher than those under RCP4.5-SSP2. During the mid-term (Fig. 4d), however, the duration of exposure can increase to more than 60 days in most of the Gran Chaco; to 30-60 days in most of Syria, Iran, Afghanistan, Pakistan, the southeastern parts of central Asia, southern Africa, the central United States, and many areas in the coastal Mediterranean region, the Sahel, southeastern Australia, northeastern Mexico, Brazil, and Argentina; and to 10-30 days in large areas of southwestern Russia, northern India, eastern China, Southeast Asia, the United States, central Brazil, and northern Argentina.

Under the RCP8.5-SSP5 scenario during the near term (Fig. 5a), the exposure is projected to be longer than that under the RCP4.5-SSP2 scenario by fewer than 10 days in most areas including sub-Saharan Africa, West Asia, northern Kazakhstan, southern China, Southeast Asia, the United States, Brazil, and Argentina, but longer by more than 10 days only in sporadic regions of northwestern China, southern Iran, southern Arica, and the Gran Chaco. Surprisingly, large areas in western Europe, southern Russia, northern China, inland Australia, eastern Brazil, and most of India, the United States, and Mexico will see shorter exposures, shorter by 1-10 days under the RCP8.5SSP5 scenario than those under the RCP4.5-SSP2 scenario. However, during the mid-term (Fig. 5b), the exposure under RCP8.5-SSP5 is longer than that under RCP4.5SSP2 by 1-10 days for most areas worldwide; by 10-30 days in most of the coastal Mediterranean areas, southern Africa, the southeastern parts of central Asia, the United
States, the Gran Chaco, and many areas in the Sahel, Iran, Afghanistan, Pakistan, northwestern China, southeastern Australia, and Brazil, as well as some parts of northwestern India, eastern China, and Southeast Asia, and by as many as 30-60 days in large areas of the northern Gran Chaco and northwestern China.

Regardless of the periods and the scenarios, areas in which maize will be exposed to extremely high temperatures for the first time are concentrated in Eastern Europe, southern Russia, northeastern and southwestern China, Indonesia, southern India, Congo, the Great Lakes region of North America, and southern Brazil. These regions of exposure are likely to spread rapidly, especially under RCP8.5-SSP5 in the mid-term, when vast areas not only at low latitudes but also at higher latitudes will experience such exposure for the first time. In contrast, only a few areas cease to experience longer exposure, and that too with only tiny margins, scattered throughout the world but concentrated mainly in West Asia and the western Amazon basin.

\subsection{Statistical Characteristics of Maize Exposure to High Temperatures}

In this section, statistical characteristics of maize exposure and their changes are analyzed from two aspects: (1) the length of exposure worldwide and in areas of varying suitability for maize cultivation; and (2) the area of exposure, in terms of both total area and areas with different lengths of exposure.

\subsubsection{Length of Exposure}

In the past, maize-growing areas worldwide were exposed to extreme heat for 16 days (area-weighted mean) during 
Fig. 5 Differences between areas in which maize is exposed to extremely high temperatures under RCP8.5-SSP5 relative to those under RCP4.5-SSP2 during a the near term (2016-2035), and b the midterm (2046-2065). NE neverexposed zones, $E 2 N$ exposed zone ceasing to be exposed, $N 2 E$ zones never exposed before but now exposed. $R C P$ representative concentration pathway, SSP shared socioeconomic pathway

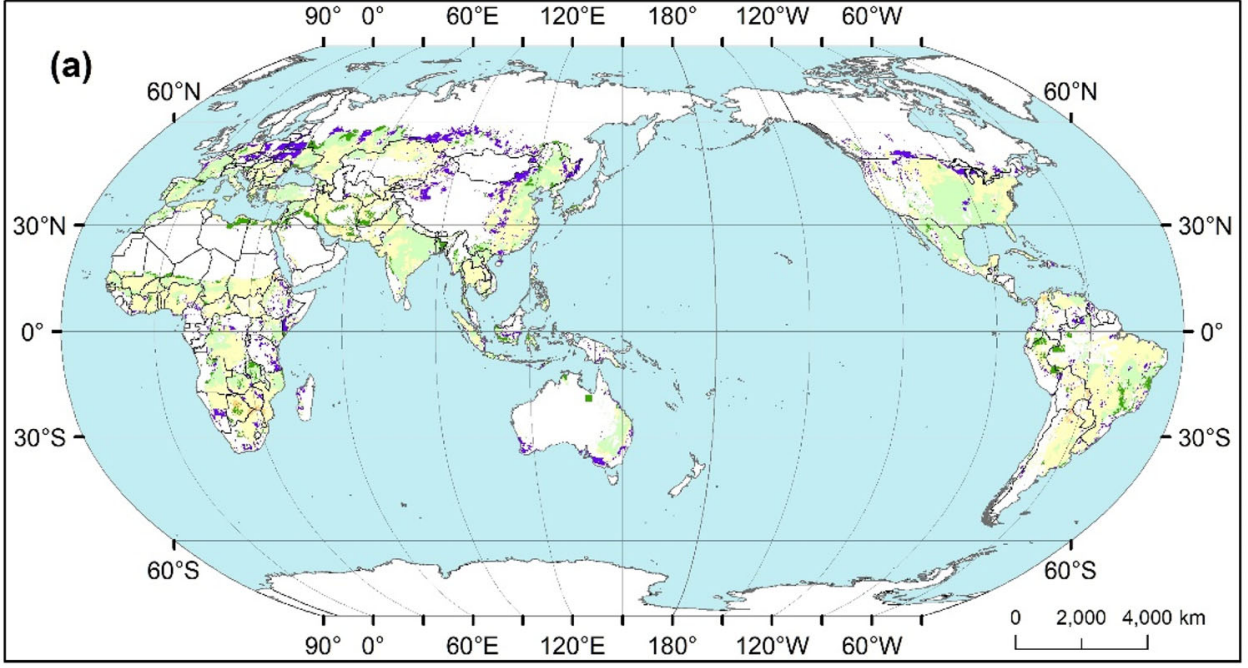

NE E2N

N2E $\square<=0$

$0-10$

$10-30$

$30-60$

$>60$ days

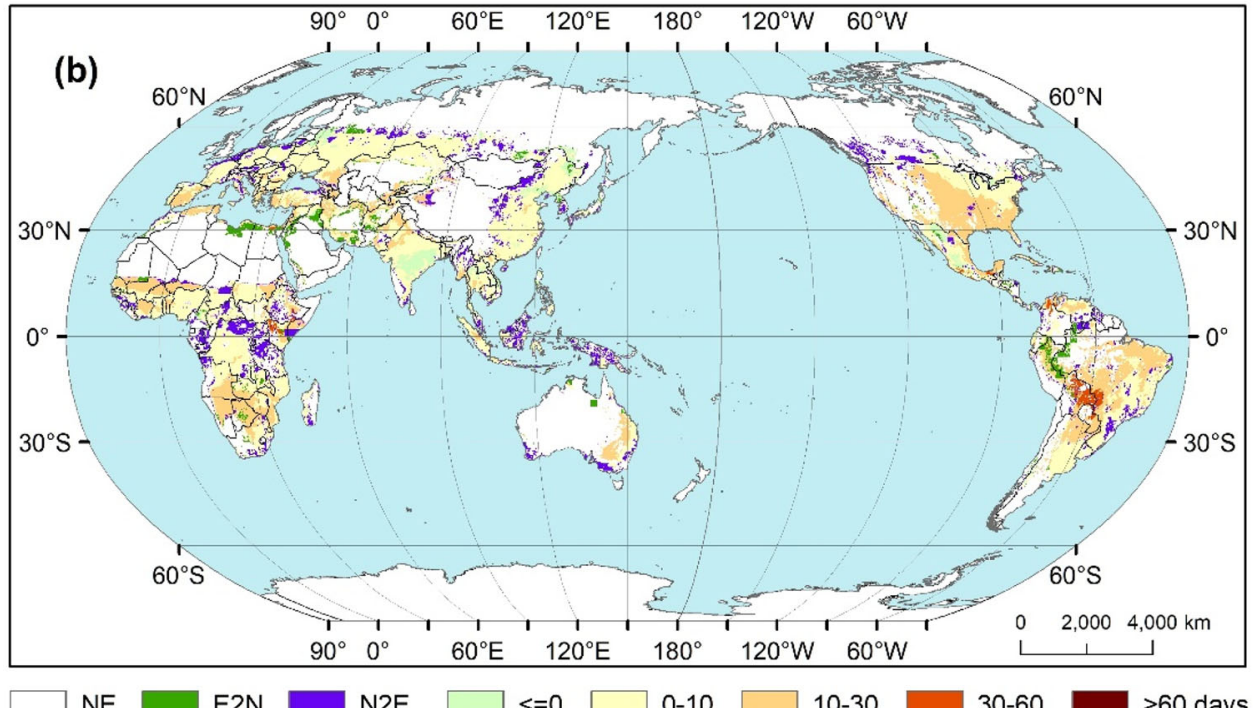

NE

$\mathrm{N} 2 \mathrm{E}-2<=0$

$0-10$

10-30

$30-60$

$>60$ days the growing season. In the near term under both RCP4.5SSP2 and RCP8.5-SSP5, that duration increases to 20 days (an increase of 25\%). The corresponding numbers for the mid-term are 24 days under RCP4.5-SSP2 and 27 days under RCP8.5-SSP5, or an increase of about $50 \%$ and $69 \%$, respectively.

The length of exposure was analyzed for areas suitable to varying degrees for maize cultivation, assuming areas not particularly suitable and those highly suitable are generally synonymous with low and high maize yields, respectively, and that regions highly suited to maize account for the lion's share of global maize production. Table 4 shows that areas highly suitable (based on biophysical factors) for maize cultivation always had shorter exposures in the past, possibly because the cooler midlatitudes are generally more suitable than the warmer low latitudes; however, it should be noted that in these very areas, the duration of exposure to extremely high temperatures may increase by up to $772.10 \%$ - and more rapidly—under RCP8.5-SSP5 during the mid-term.

\subsubsection{Area of Exposure}

The total area over which maize was exposed to extremely high temperatures during the growing season was 108.16 million ha in the past (Table 5). Under RCP4.5-SSP2, the area increases to 179.21 million ha, or by $65.69 \%$, in the near term and nearly triples to reach 289.75 million ha (increase of 167.89\%) in the mid-term. Under RCP8.5SSP5, the total exposure area will nearly double (increase by $74.51 \%$ ) to 188.75 million ha in the near term and almost triple (increase by $184.93 \%$ ) to 308.18 million ha in 


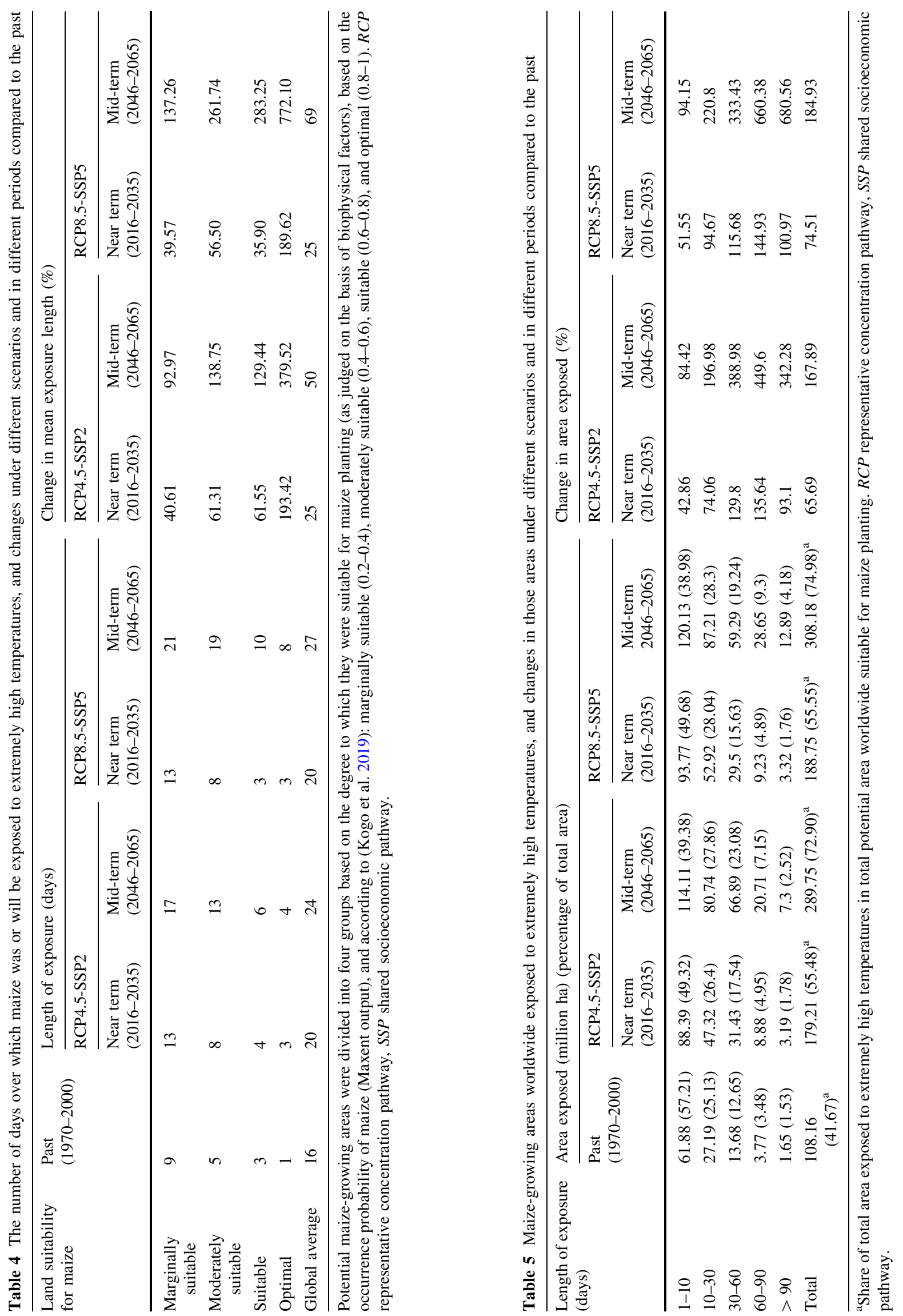


the mid-term. In the past, the total affected area was estimated to account for nearly half $(41.67 \%)$ of the simulated total cultivated area under maize worldwide. That proportion increases to slightly more than half (about 55\%) under both RCP4.5-SSP2 and RCP8.5-SSP5 in the near term, and to nearly three quarters $(74 \%)$ by the mid-term.

In terms of the length or duration of exposure, the proportion of area exposed for 1-10 days was always maximum irrespective of the scenario or the period, followed, in descending order, by areas with exposure of 10-30 days, 30-60 days, 60-90 days, and above 90 days. However, this order and the length change markedly in the future. The share of areas with exposure of 1-10 days decreases from $57.21 \%$ in the past to $38.98 \%$ under RCP8.5-SSP5 scenario in the mid-term. In contrast, the share of areas exposed for 10-30 days remains more or less the same, at 27\%, and that of areas exposed for 30-60 days increases slightly from nearly $13 \%$ in the past to approximately $16 \%$ in the near term, and to $21 \%$ in the mid-term. The shares of areas exposed for 60-90 days and for more than 90 days both show a marked increase, almost triple their respective shares in the past, under RCP8.5-SSP5 in the mid-term.

All the areas, irrespective of the length of exposure, continue to increase, although with major differences among them. Compared to the past, the areas exposed for 60-90 days increase the fastest, by nearly $150 \%$ during the near term and by about $450 \%$ and $660 \%$ in the mid-term under RCP4.5-SSP2 and RCP8.5-SSP5 scenarios, respectively. Next, in descending order, are areas exposed for 30-60 days, more than 90 days, and 10-30 days, all of which increase by generally over $100 \%$ in the near term and by more than $200 \%$ in the mid-term. Areas exposed for 1-10 days, although the slowest to increase, do so by about $45 \%$ in the near term and by about $90 \%$ in the mid-term. The only exception is that under RCP8.5-SSP5 in the midterm, areas exposed for more than 90 days record the steepest increase, by as much as $680.56 \%$.

Table 5 also shows that during the same future periods, the changes relative to the past are generally greater under RCP8.5-SSP5 than under RCP4.5-SSP2 in terms of both total area and areas with different lengths of exposure. Such differences are especially obvious in the mid-term but only slight in the near term. Under a given RCP-SSP scenario, such changes are greater in the mid-term than in the near term, especially under RCP8.5-SSP5.

\section{Discussion}

In this section, we examine the accuracy of our predictions of potential maize distribution, and then compare our projections of maize exposure with previous studies.
Finally, we discuss the advantages and limitations of our research work.

\subsection{Accuracy of Predictions Related to Maize Distribution Worldwide}

Because reliable estimates of the potential distribution of maize-growing areas are the basis for evaluating the impact of extreme heat on the crop, we examined the results of simulating the past distribution before analyzing the exposure. To begin with, all the AUC values from the Maxent model were close to 0.75 , which is an acceptable level, indicating that the Maxent model, after training it, had performed well overall (Phillips and Dudik 2008) and can predict reliably the areas suitable for maize cultivation as determined by the chosen biophysical factors.

Further, Fig. 6 shows that, generally, the FMHA values were closely and positively correlated to the probabilities of maize being cultivated in a given grid cell in the past, as predicted by Maxent. That is to say, the grid cells with high (or low) FMHA values are also likely to have high (or low) probability of maize being cultivated in those grid cells. This proves that the probabilities as predicted by Maxent generally match the situation in the past.

Finally, we examined the spatial consistency between the simulated and the actual distribution of maize as shown on a map giving the values of FMHA (Monfreda et al. 2008) (Fig. 7). The overlay analysis showed that of all cells under maize planting, $83.12 \%$ were correctly predicted as potentially likely to be under maize. In contrast, cells in which maize had been grown in the past but were missing from the predictions accounted for only $16.88 \%$ of the total number of cells, distributed sporadically in northern Russia, northeastern, northwestern, and southwestern China, Indonesia, southern Africa, the western United States, and so on-areas with a mean FMHA of only $0.79 \%$ and thus

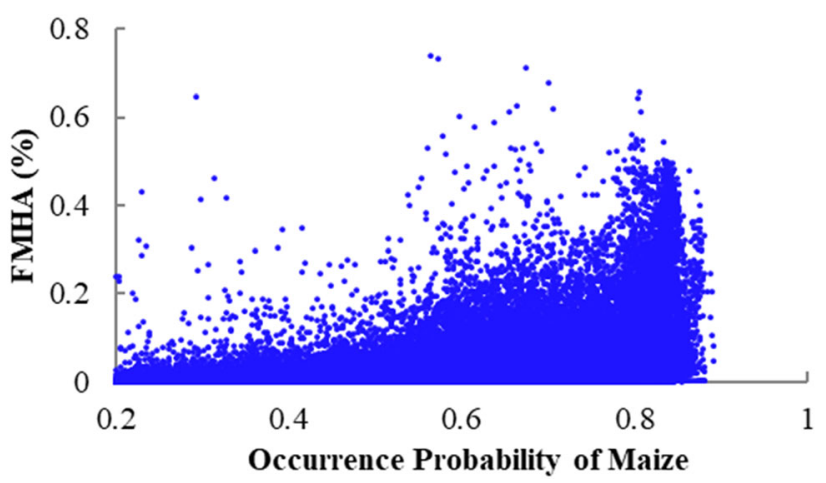

Fig. 6 Scatterplot showing the correspondence between the occurrence probability of maize ( $x$ axis), simulated using the Maxent model, and the FMHA (fraction of maize-harvested area) value ( $y$ axis) within the corresponding grid cell. The $R^{2}$ for the scatterplot is 0.1384 
Fig. 7 Spatial consistency between areas simulated to be cultivated with maize and areas in which maize was grown during the 2000 s

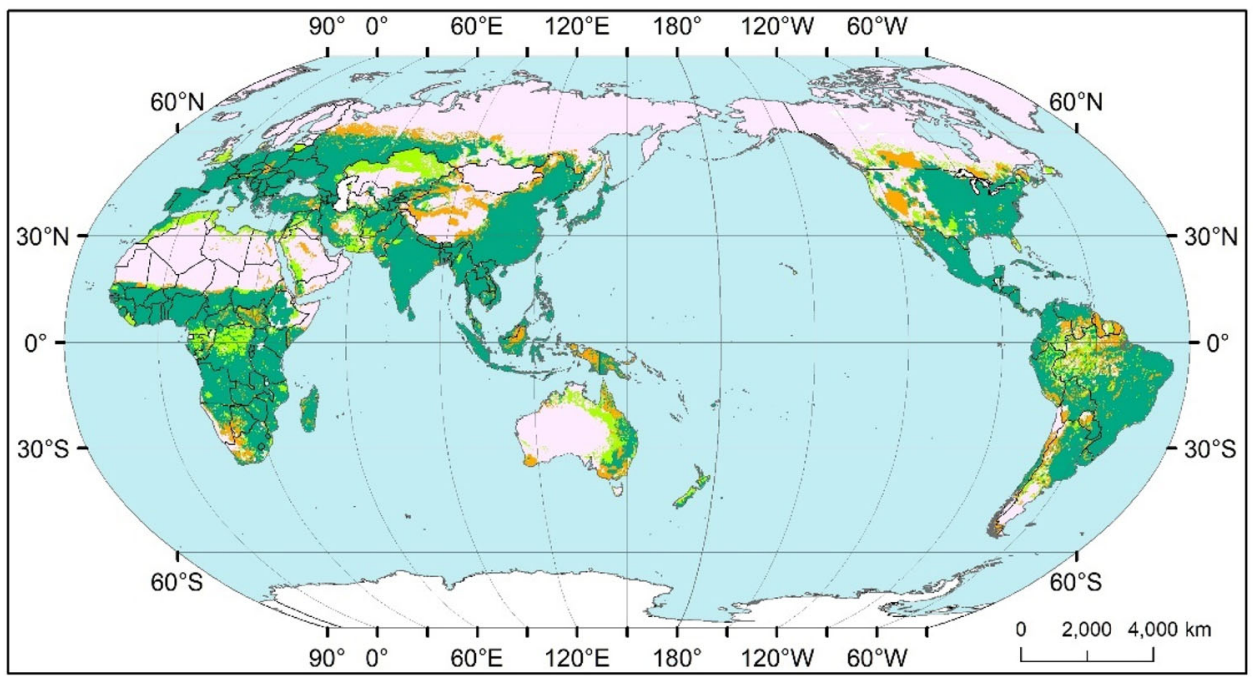

$\square$ Unpredicted, No harvest $\square$ Unpredicted, Harvested $\square$ Predicted, No harvest $\square$ Predicted, Harvested can be reasonably considered unsuitable for maize, although measures such as irrigation and stress-tolerant cultivars may have played a role in overcoming the environmental constraints and making maize cultivation possible (Swastika et al. 2004; Badu-Apraku and Fakorede 2013; Zhang et al. 2017).

But maize was never grown on $14.75 \%$ of the cells that were predicted to be potentially suitable, including some areas in northern Kazakhstan, the Amazon basin, the Congo basin, inland Australia, and so on. With the data by Hurtt et al. (2020), we found that actually the areal proportion of C4 crops in such cells was only $0.39 \%$. Possible reasons for this discrepancy include local choice of the crop (for example, wheat is predominant in Australia).

Based on the above findings, we consider our estimates of the potential distribution of maize to be reasonable and reliable.

\subsection{Comparisons with Existing Projections of Exposure}

The assessment carried out in the present study is broadly in agreement with that carried out by Gourdji et al. (2013), which reported that maize suffered frequent exposure to critically high temperatures at diverse locations including in the United States, Mexico, Argentina, parts of sub-Saharan Africa and the Nile basin, South Asia, and China. Gourdji et al. (2013) also predicted large increases in such exposure at most locations globally, with significant increases in Eastern Europe, the Nile basin, Argentina, the United States, and Mexico. Similar to our results, Teixeira et al. (2013) also predicted increase in the intensity and the extent of heat stress for maize, especially in northern India, the Sahel, southeastern Africa, and the central parts of south America. Thus, our estimates generally agree with those from earlier studies with reference to the trends and hotspots of maize exposure.

However, we should also acknowledge several differences between our findings and those from earlier studies. A new and noteworthy finding of our study is that areas such as West Asia and the western Amazon basin may see marked reduction in exposure, whereas areas at both low and high latitudes are likely to be exposed for the first time, especially under the higher pathway scenarios in the long term. Statistically, our estimates of the length of exposure and its extent are higher than those of Gourdji et al. (2013) and Teixeira et al. (2013). Both these studies maintain that maize is exposed to extremely high temperatures only over small areas under the baseline climatic conditions.

One primary and plausible reason for these disparities is that we coupled climate change and the alterations of crop distribution in our assessment of exposure instead of focusing only on the adverse effects of the rise in temperature. The result of exposure assessment is largely dependent on the projected crop distribution because only in areas that grow the crop can it be exposed to climatic hazards. For example, under RCP8.5-SSP5, 4,831 cells are predicted to be no longer exposed to extreme heat, of which 4,747 cells, or $98.26 \%$, are predicted to be without any area under maize and therefore cannot be exposed despite the existence of extremely high temperatures. The distribution of a crop can change dramatically and frequently because of many and various factors, such as cropland being abandoned as a result of changes in climate (Blair et al. 2018), urbanization, and industrialization (Yan et al. 2016), and cropland being expanded following deforestation (Noojipady et al. 2017) and land reclamation (Griffiths et al. 2013). Failing to consider crop distribution 
dynamically can lead to erroneous estimates of exposure. Thus, our study takes one step forward by integrating both climate change and the variations of crop distribution.

Another important reason is that we calculated the exposure over the entire growth period of maize instead of confining the calculations to the reproductive period. This difference led to our estimates of the exposure being higher. Differences in what is considered the threshold of extreme heat, in the periods studied, and in the climate scenarios chosen also account for some of the differences.

\subsection{Advantages and Limitations}

Using maize as an example, we aimed at more accurate assessment of a crop's exposure to climatic hazards within a dynamic and scalable framework by taking into account not only changes in the climatic hazard itself (the hazard dimension) but also the distribution of the crop (the elements at risk dimension). The predicted distribution and exposure of maize were generally close to both actual values and to the findings of earlier research, thereby proving the new methodology that we adopted to be reliable. Our projections of the exposure of maize, a staple of many regions worldwide, have major implications for global and regional food production and sustainable development. We also emphasize that our method, after appropriate revisions, can be extended to other crops. The present study thus makes a major contribution in methodology to the dynamic assessment of the exposure of crops to climatic hazards in the context of climate change.

Among the three components of risk assessment (IPCC 2014) — hazard, exposure, and vulnerability—exposure has been considered an important prerequisite to viewing a specific vulnerability as vital (Anandhi et al. 2016) and as a major driver of the formation and increases of losses (Bouwer 2011; Bouwer 2013; Shi et al. 2014). Although the elements at risk, such as people or economic assets, may be exposed but not vulnerable, the degree of risk from disasters due to extreme hazards has been increasingly shown to be a consequence of exposure (UNISDR 2015). Thus, our research on the assessment of exposure can be important to laying the basis for more accurate assessment and governance of risks to crop production.

This study also has some limitations and can be improved in future research. First, on the hazard dimension, the intensity of extreme heat was calculated over the entire growth period of maize and taking a single value, $37{ }^{\circ} \mathrm{C}$, as the threshold. However, the threshold can vary depending on the stage of growth (Luo 2011; Sanchez et al. 2014). The thresholds and the growth stages of maize can vary among maize cultivars grown worldwide (Bussel et al. 2015), or as a result of changes in the physiological traits of maize caused by varietal improvement (Banziger et al.
2006). Thus, our estimates of the intensity of extreme heat, and of the exposure, could be biased. For example, the severity of exposure may be underestimated for the grain filling phase of maize, with a lethal maximum temperature of $36^{\circ} \mathrm{C}$ (Sanchez et al. 2014). It is necessary to evaluate maize exposure to extreme heat by growth stages, with local variety traits and the crop calendar considered simultaneously. Because the present study was conducted on a global scale and focused on the accurate prediction of spatial patterns of exposure, we had to ignore the above differences; data on regional differences or potential changes in the physiological requirements and on the periods of maize cultivation are not easily available. However, future studies should consider these factors, if the required data are available, to produce more reliable results.

Second, on the elements at risk dimension, our predictions of the distribution of maize can also introduce uncertainties. Specifically, the suitability of land for maize can be different from the results of our simulation considering the increasing deployment of stress-tolerant maize cultivars (Cooper et al. 2014; Prasanna 2016). Despite the decisive effect of biophysical factors, socioeconomic factors such as population, economy, policy, culture, technology, and education can also influence food supply and demand, crop choices, and so on, and ultimately the actual distribution of a crop on a local scale (Schroth and Ruf 2013; Ureta et al. 2013; Eaton et al. 2018). However, only land use was considered in this study, considering the difficulties in quantifying the effects of other socioeconomic factors on maize cultivation. Inclusion of such factors is required for more accurate projections of the distribution of a crop and of its exposure, but is possible only if the required data are available at sufficiently high temporal and spatial resolutions, along with reliable methods of quantifying the impacts of those factors. A possible solution to promoting the prediction accuracy is to allocate the future maize production to grid cells by considering both its planting suitability (mainly influenced by climate change) and the required cultivation area (determined by the supply and demand under given socioeconomic conditions). This would require not only highprecision projection data on climate and socioeconomic changes, but also the establishment of quantitative relationships between maize yield, consumption, and socioeconomic variables, including population, GDP, irrigation, fertilization, and so on.

As mentioned in Sect. 2.2.2, for grids with maize distribution, we used reconstructed and projected cultivated area under $\mathrm{C} 4$ crops as a proxy for maize in estimating the area exposed to extremely high temperatures. This decision was governed by the difficulties in predicting the actual planting area of maize within each grid under climate and 
socioeconomic changes, and was reasonable to some extent considering that the global area under maize planting (FAO 2018) has been accounting for a high, rising proportion of the area under all the $C 4$ crops (Hurtt et al. 2020) (43.98-62.35\% from the year 1961-2015). We realize, however, that the assumption can inevitably result in the potential area under maize being overestimated and bringing uncertainty to the projection of the total area exposed to extreme heat (Sect. 3.2.2). This can be especially obvious for regions where $\mathrm{C} 4$ crops other than maize are cultivated, including Congo, Saudi Arabia, Australia, Japan, and so on.

Finally, the adverse impacts of maize exposure to extreme heat can be intensified by the interactions between heat and other forms of stress such as drought. Maize is cultivated mainly in semiarid environments in which water scarcity and high temperatures usually occur simultaneously (Hu et al. 2015). Under conditions of water stress, canopy temperatures can be higher than air temperatures, and heat has been shown to be more damaging to maize yields under dry than under normal conditions (Matiu et al. 2017). Based on these points, our consideration of only maximum temperature effects might be unwarranted in many drought-prone regions such as sub-Saharan Africa and the North China Plain. In future research, both microand macro-analyses should be essential to better understand and accurately quantify the combined effects of heat and other stresses (such as drought, excessive rainfall). For example, laboratory tests (Hu et al. 2015) can be performed to understand the mechanism of maize cultivars' responses to the stresses, and statistical approaches (Matiu et al. 2017) can also be used to distinguish the interacting effects of temperature and drought on maize yields.

\section{Conclusion}

Accurately assessing a crop's exposure to extreme heat can provide a scientific basis for evaluating the risk to crop production and for ensuring food security, and thus has become urgent in the context of climate change. This study projected the distribution and changes of the exposure of maize to extremely high temperatures worldwide by integrating climate change and the alterations of the distribution of maize-growing areas through three steps: (1) calculating the intensity of the hazard in the form of high temperatures, (2) predicting the potential distribution of maize-growing areas, and (3) quantifying the exposure of maize to extremely high temperatures.

Spatially, the subtropical areas, including West Asia, South Asia, the Sahel, southern Africa, the United StatesMexico border region, the Gran Chaco, and so on are always the hotspots of maize exposure. With climate change and changes in the distribution of maize-growing areas, not only these areas will experience increasingly severe exposure but also the mid-latitude regions such as the North China Plain and the central United States may see sharp increases in exposure. Many areas at both high and low latitudes may change from being non-exposed to exposed. Statistically, both the mean length of the exposure and the total area experiencing such exposure will continue to increase markedly, with dramatic increase in areas facing more intense exposure. Areas particularly well-suited to maize planting will experience the most rapid increase in the length of exposure. The exposure will be more intense under higher emission pathways and in the longer future.

This study serves as a warning that extreme heat poses a serious threat to global and regional maize production, and it is imperative that early measures be taken to lower the risk of failed production. Such measures should include not only mitigation efforts to combat global warming and to reduce warm extremes but also adaptive strategies such as developing cultivars tolerant to heat and heat-related forms of stress and moving maize cultivation to cooler regions.

Acknowledgments We are grateful to the Frederick S. Pardee Center for the Study of the Longer-Range Future and the Department of Earth and Environment at Boston University for general support to Yuan Gao for conducting this research. We thank Qi Zhang for useful discussions and constructive comments on overall research design. This study was supported by the National Key Research and Development Program of China (Grant No. 2016YFA0602402).

Open Access This article is licensed under a Creative Commons Attribution 4.0 International License, which permits use, sharing, adaptation, distribution and reproduction in any medium or format, as long as you give appropriate credit to the original author(s) and the source, provide a link to the Creative Commons licence, and indicate if changes were made. The images or other third party material in this article are included in the article's Creative Commons licence, unless indicated otherwise in a credit line to the material. If material is not included in the article's Creative Commons licence and your intended use is not permitted by statutory regulation or exceeds the permitted use, you will need to obtain permission directly from the copyright holder. To view a copy of this licence, visit http://creativecommons. org/licenses/by/4.0/.

\section{References}

Anandhi, A., J.L. Steiner, and N. Bailey. 2016. A system's approach to assess the exposure of agricultural production to climate change and variability. Climatic Change 136(3-4): 647-659.

Araújo, M.B., and A. Guisan. 2006. Five (or so) challenges for species distribution modelling. Journal of Biogeography 33(10): $1677-1688$.

Badu-Apraku, B., and M.A.B. Fakorede. 2013. Breeding early and extra-early maize for resistance to biotic and abiotic stresses in Sub-Saharan Africa. In Plant breeding reviews, ed. J. Janick, 123-205. New Jersey: John Wiley.

Baker, N.T., and P.D. Capel. 2011. Environmental factors that influence the location of crop agriculture in the conterminous 
United States. U.S. Geological Survey Scientific Investigations Report 2011-5108. Reston, VA: USGS.

Banziger, M., P.S. Setimela, D. Hodson, and B. Vivek. 2006. Breeding for improved abiotic stress tolerance in maize adapted to southern Africa. Agricultural Water Management 80(1-3): 212-224.

Batjes, N.H. 2016. Harmonized soil property values for broad-scale modelling (WISE30sec) with estimates of global soil carbon stocks. Geoderma 269: 61-68.

Blair, D., C. Shackleton, and P. Mograbi. 2018. Cropland abandonment in South African smallholder communal lands: Land cover change (1950-2010) and farmer perceptions of contributing factors. Land 7(4): 121.

Bouwer, L.M. 2011. Have disaster losses increased due to anthropogenic climate change?. Bulletin of the American Meteorological Society 92(1): 39-46.

Bouwer, L.M. 2013. Projections of future extreme weather losses under changes in climate and exposure. Risk Analysis 33(5): 915-930.

Cooper, M., C. Gho, R. Leafgren, T. Tang, and C. Messina. 2014. Breeding drought-tolerant maize hybrids for the US corn-belt: Discovery to product. Journal of Experimental Botany 65(21): 6191-6204.

Danielson, J.J., and D.B. Gesch. 2011. Global multi-resolution terrain elevation data 2010 (GMTED2010). U.S. Geological Survey open-file report 2011-1073. Reston, VA: USGS.

Dhondt, S., C. Beckx, B. Degraeuwe, W. Lefebvre, B. Kochan, T. Bellemans, L.I. Panis, C. Macharis, and K. Putman. 2012. Health impact assessment of air pollution using a dynamic exposure profile: Implications for exposure and health impact estimates. Environmental Impact Assessment Review 36: 42-51.

Eaton, W.M., M. Burnham, C.C. Hinrichs, T. Selfa, and S. Yang. 2018. How do sociocultural factors shape rural landowner responses to the prospect of perennial bioenergy crops? Landscape and Urban Planning 175: 195-204.

Elith, J., and J.R. Leathwick. 2009. Species distribution models: Ecological explanation and prediction across space and time. Annual Review of Ecology, Evolution, and Systematics 40(1): 677-697.

Elith, J., C.H. Graham, R.P. Anderson, M. Dudık, S. Ferrier, A. Guisan, R.J. Hijmans, and F. Huettmann et al. 2006. Novel methods improve prediction of species' distributions from occurrence data. Ecography 29(2): 129-151.

Elith, J., S.J. Phillips, T. Hastie, M. Dudik, Y.E. Chee, and C.J. Yates. 2011. A statistical explanation of MaxEnt for ecologists. Diversity and Distributions 17(1): 43-57.

Evans, J.M., R.J. Fletcher, and J. Alavalapati. 2010. Using species distribution models to identify suitable areas for biofuel feedstock production. Global Change Biology Bioenergy 2(2): 63-78.

FAO (Food and Agriculture Organization of the United Nations). 2018. FAOSTAT. http://www.fao.org/faostat/en/\#data/QC. Accessed 25 Sept 2020.

Fischer, G., F. Nachtergaele, S. Prieler, H.T. van Velthuizen, L. Verelst, and D. Wiberg. 2008. Global agro-ecological zones assessment for agriculture (GAEZ 2008). Laxenburg, Austria and Rome, Italy: IIASA and FAO.

Fourcade, Y., J.O. Engler, D. Rodder, and J. Secondi. 2014. Mapping species distributions with MAXENT using a geographically biased sample of presence data: A performance assessment of methods for correcting sampling bias. PLoS One 9(5): Article e97122.

Freire, S., and C. Aubrecht. 2012. Integrating population dynamics into mapping human exposure to seismic hazard. Natural Hazards and Earth System Sciences 12(11): 3533-3543.
Gourdji, S.M., A.M. Sibley, and D.B. Lobell. 2013. Global crop exposure to critical high temperatures in the reproductive period: Historical trends and future projections. Environmental Research Letters 8(2): Article 024041.

Griffiths, P., D. Muller, T. Kuemmerle, and P. Hostert. 2013. Agricultural land change in the Carpathian ecoregion after the breakdown of socialism and expansion of the European Union. Environmental Research Letters 8(4): Article 045024.

Hatfield, J.L., K.J. Boote, B.A. Kimball, L.H. Ziska, R.C. Izaurralde, D. Ort, A.M. Thomson, and D. Wolfe. 2011. Climate impacts on agriculture: Implications for crop production. Agronomy Journal 103(2): 351-370.

He, Q., G. Zhou, X. Lü, and M. Zhou. 2019. Climatic suitability and spatial distribution for summer maize cultivation in China at 1.5 and $2.0^{\circ} \mathrm{C}$ global warming. Science Bulletin 64(10): 690-697.

Hijmans, R.J., S.E. Cameron, J.L. Parra, P.G. Jones, and A. Jarvis. 2005. Very high resolution interpolated climate surfaces for global land areas. International Journal of Climatology 25(15): 1965-1978.

Hu, X., L. Wu, F. Zhao, D. Zhang, N. Li, G. Zhu, C. Li, and W. Wang. 2015. Phosphoproteomic analysis of the response of maize leaves to drought, heat and their combination stress. Frontiers in Plant Science 6: Article 298.

Hurtt, G.C., L. Chini, R. Sahajpal, S. Frolking, B.L. Bodirsky, K. Calvin, J.C. Doelman, and J. Fisk et al. 2020. Harmonization of global land use change and management for the period 850-2100 (LUH2) for CMIP6. Geoscientific Model Development 13(11): $5425-5464$

IPCC (Intergovernmental Panel on Climate Change). 1996. Climate change 1995: Impacts, adaptations and mitigation of climate change: Scientific-technical analyses. Contribution of Working Group II to the Second Assessment Report of the Intergovernmental Panel on Climate Change, ed. R.T. Watson, M.C. Zinyowera, and R.H. Moss. Cambridge and New York: Cambridge University Press.

IPCC (Intergovernmental Panel on Climate Change). 2014. Climate change 2014: Impacts, adaptation, and vulnerability. Part A: Global and sectoral aspects. Contribution of Working Group II to the Fifth Assessment Report of the Intergovernmental Panel on Climate Change, ed. C.B. Field, V.R. Barros, D.J. Dokken, K.J. Mach, M.D. Mastrandrea, T.E. Bilir, M. Chatterjee, K.L. Ebi, et al. Cambridge and New York: Cambridge University Press.

Kogo, B.K., L. Kumar, R. Koech, and C.S. Kariyawasam. 2019. Modelling climate suitability for rainfed maize cultivation in Kenya using a Maximum Entropy (MaxENT) approach. Agronomy-Basel 9(11): Article 727.

Kullback, S., and R.A. Leibler. 1951. On information and sufficiency. The Annals of Mathematical Statistics 22(1): 79-86.

Lobell, D.B., G.L. Hammer, G. McLean, C. Messina, M.J. Roberts, and W. Schlenker. 2013. The critical role of extreme heat for maize production in the United States. Nature Climate Change 3(5): 497-501.

Long, S.P., and A.K. Spence. 2013. Toward cool C4 crops. Annual Review of Plant Biology 64: 701-722.

Luo, Q.Y. 2011. Temperature thresholds and crop production: A review. Climatic Change 109(3-4): 583-598.

Matiu, M., D.P. Ankerst, and A. Menzel. 2017. Interactions between temperature and drought in global and regional crop yield variability during 1961-2014. PLoS One 12(5): Article e0178339.

Monfreda, C., N. Ramankutty, and J.A. Foley. 2008. Farming the planet: 2. Geographic distribution of crop areas, yields, physiological types, and net primary production in the year 2000 . Global Biogeochemical Cycles 22 (1): Article GB1022. 
Noojipady, P., C.D. Morton, N.M. Macedo, C.D. Victoria, C.Q. Huang, K.H. Gibbs, and L.E.Bolfe. 2017. Forest carbon emissions from cropland expansion in the Brazilian Cerrado biome. Environmental Research Letters 12(2): Article 025004.

Phillips, S.J., and M. Dudik. 2008. Modeling of species distributions with Maxent: New extensions and a comprehensive evaluation. Ecography 31(2): 161-175.

Phillips, S.J., R.P. Anderson, and R.E. Schapire. 2006. Maximum entropy modeling of species geographic distributions. Ecological Modelling 190(3-4): 231-259.

Pittore, M., M. Wieland, and K. Fleming. 2016. Perspectives on global dynamic exposure modelling for geo-risk assessment. Natural Hazards 86(S1): 7-30.

Prasanna, B.M. 2016. Developing and deploying abiotic stresstolerant maize varieties in the tropics: Challenges and opportunities. In Molecular breeding for sustainable crop improvement, ed. V.R. Rajpal, S.R. Rao, and S.N. Raina, 61-77. Cham: Springer International Publishing.

Ramirez-Cabral, N.Y.Z., L. Kumar, and F. Shabani. 2017. Global alterations in areas of suitability for maize production from climate change and using a mechanistic species distribution model (CLIMEX). Scientific Reports 7(1): Article 5910.

Ranum, P., J.P. Peña-Rosas, and M.N. Garcia-Casal. 2014. Global maize production, utilization, and consumption. Annals of the New York Academy of Sciences 1312(1): 105-112.

Sacks, W.J., D. Deryng, J.A. Foley, and N. Ramankutty. 2010. Crop planting dates: An analysis of global patterns. Global Ecology and Biogeography 19(5): 607-620.

Sanchez, B., A. Rasmussen, and J.R. Porter. 2014. Temperatures and the growth and development of maize and rice: A review. Global Change Biology 20(2): 408-417.

Schroth, G., and F. Ruf. 2013. Farmer strategies for tree crop diversification in the humid tropics: A review. Agronomy for Sustainable Development 34(1): 139-154.

Shabani, F., and B. Kotey. 2016. Future distribution of cotton and wheat in Australia under potential climate change. Journal of Agricultural Science 154(2): 175-185.

Shi, P. 2019. Disaster risk science, 2nd edn. Singapore and Beijing: Springer and Beijing Normal University Press.

Shi, P., S. Sun, M. Wang, N. Li, J.A. Wang, Y.Y. Jin, X.T. Gu, and W.X. Yin. 2014. Climate change regionalization in China (1961-2010). Science China Earth Sciences 57(11): 2676-2689.

Stone, P. 2001. The effects of heat stress on cereal yield and quality. In Crop responses and adaptations to temperature stress, ed. A.S. Basra, 243-291. Binghamton, New York: Food Products Press.

Su, P., A. Zhang, R. Wang, J.A. Wang, Y. Gao, and F. Liu. 2021. Prediction of future natural suitable areas for rice under Representative Concentration Pathways (RCPs). Sustainability 13(3): Article 1580.

Sun, J.S., G.S. Zhou, and X.H. Sui. 2012. Climatic suitability of the distribution of the winter wheat cultivation zone in China. European Journal of Agronomy 43: 77-86.

Swastika, D.K.S., F. Kasim, W. Sudana, R. Hendayana, K. Suhariyanto, R. Gerpacio, and P. Pingali. 2004. Maize in Indonesia: Production systems, constraints, and research priorities. Texcoco, Mexico: CIMMYT (International Maize and Wheat Improvement Center).

Teixeira, E.I., G. Fischer, H. van Velthuizen, C. Walter, and F. Ewert. 2013. Global hot-spots of heat stress on agricultural crops due to climate change. Agricultural and Forest Meteorology 170: 206-215.

Thrasher, B., and R. Nemani. 2012. NASA earth exchange global daily downscaled projections (NEX-GDDP). https://www.nccs. nasa.gov/services/data-collections/land-based-products/nexgddp. Accessed 28 Aug 2017.

UNISDR (United Nations Office for Disaster Risk Reduction). 2015. Global assessment report on disaster risk reduction 2015 Making development sustainable: The future of disaster risk management. New York: United Nations.

Ureta, C., C. González-Salazar, E.J. González, E.R. Álvarez-Buylla, and E. Martínez-Meyer. 2013. Environmental and social factors account for Mexican maize richness and distribution: A data mining approach. Agriculture, Ecosystems and Environment 179: 25-34.

Ureta, C., E. Martínez-Meyer, H.R. Perales, and E.R. Álvarez-Buylla. 2012. Projecting the effects of climate change on the distribution of maize races and their wild relatives in Mexico. Global Change Biology 18(3): 1073-1082.

van Bussel, L.G.J., E. Stehfest, S. Siebert, C. Müller, and F. Ewert. 2015. Simulation of the phenological development of wheat and maize at the global scale. Global Ecology and Biogeography 24(9): 1018-1029.

Wahid, A., S. Gelani, M. Ashraf, and M.R. Foolad. 2007. Heat tolerance in plants: An overview. Environmental and Experimental Botany 61(3): 199-223.

Wang, B., P.Y. Feng, D.L. Liu, and C. Waters. 2020. Modelling biophysical vulnerability of wheat to future climate change: A case study in the eastern Australian wheat belt. Ecological Indicators 114: Article 106290.

Wang, R., Y. Jiang, P. Su, and J.A. Wang. 2019. Global spatial distributions of and trends in rice exposure to high temperature. Sustainability 11(22): Article 6271.

Warszawski, L., K. Frieler, V. Huber, F. Piontek, O. Serdeczny, and J. Schewe. 2014. The Inter-Sectoral Impact Model Intercomparison Project (ISI-MIP): Project framework. Proceedings of the National Academy of Sciences 111(9): 3228-3232.

Yan, J.Z., Z.Y. Yang, Z.H. Li, X.B. Li, L.J. Xin, and L.X. Sun. 2016. Drivers of cropland abandonment in mountainous areas: A household decision model on farming scale in Southwest China. Land Use Policy 57: 459-469.

Yue, Y., P. Zhang, and Y. Shang. 2019. The potential global distribution and dynamics of wheat under multiple climate change scenarios. Science of the Total Environment 688: 1308-1318.

Zabel, F., B. Putzenlechner, and W. Mauser. 2014. Global agricultural land resources - A high resolution suitability evaluation and its perspectives until 2100 under climate change conditions. PLoS One 9(9): Article e107522.

Zhang, G.Q., C.W. Liu, C.H. Xiao, R.Z. Xie, B. Ming, P. Hou, G.Z. Liu, and W.J. Xu et al. 2017. Optimizing water use efficiency and economic return of super high yield spring maize under drip irrigation and plastic mulching in arid areas of China. Field Crops Research 211: 137-146.

Zhang, L., B.Y. Yang, S. Li, Y.Y. Hou, and D.P. Huang. 2018. Potential rice exposure to heat stress along the Yangtze River in China under RCP8.5 scenario. Agricultural and Forest Meteorology 248: 185-196.

Zhang, L., Z. Zhang, Y. Chen, X. Wei, and X. Song. 2018. Exposure, vulnerability, and adaptation of major maize-growing areas to extreme temperature. Natural Hazards 91(3): 1257-1272. 